\title{
A Comparative Clinical Evaluation of Efficacy of Midazolam as an Adjuvant to Bupivacaine in Brachial Plexus Block by Supraclavicular Approach for Upper Limb Surgery
}

\author{
Dhakal $Y^{1}$, Rajbhandari $R^{2}$, Agarwal $\mathrm{TN}^{3}$
}

\begin{abstract}
Introduction: Brachial plexus block is useful as a sole regional anesthetic technique for upper limb surgeries. Adjuvants to local anesthesia may enhance quality and duration of analgesia. Our study aimed to evaluate efficacy and safety of midazolam added to brachial plexus block. Methods: A prospective, randomized, double blind study was conducted on 60 ASA I or II adult patients undergoing upper limb surgeries under single-shot supraclavicular brachial plexus block. Patients were randomly divided into two groups. Patients in Group B $(n=30)$ were administered $30 \mathrm{~mL}$ of $0.5 \%$ bupivacaine and Group BM $(n=30)$ were given $30 \mathrm{~mL}$ of $0.5 \%$ bupivacaine with midazolam $2 \mathrm{mg}$. Hemodynamic variables (i.e., heart rate, noninvasive blood pressure), pain scores, onset of motor and sensory block, duration of analgesia and sedation score and were recorded intraoperatively and postoperatively. Results: The duration of analgesia was significantly prolonged $(P<0.05)$ in midazolam group ( $394.50 \pm 46.874)$ compared to control group $(243 \pm$ $57.545)$. Similarly, pain scores were significantly lower in group BM than in group $B(P<0.05)$. The onset of motor and sensory block, sedation score and hemodynamic variables were comparable between groups. No adverse events were observed during study. Conclusion: Addition of midazolam to bupivacaine for brachial plexus block prolongs the duration of analgesia with lower pain scores during post-operative period.
\end{abstract}

Keywords: Adjuvants, bupivacaine, midazolam, supraclavicular brachial plexus block

\section{INTRODUCTION}

Brachial Plexus Block is a feasible alternative to general anaesthesia for upper limb surgeries. The profound muscular relaxation provides good operating conditions and the intense analgesia which extends into the post-operative period decreases the demand for pain relief. Intraoperative hemodynamics are better maintained and the associated sympathetic block decreases vasospasm, edema and postoperative pain ${ }^{1}$. There are various approaches to block the brachial plexus namely the interscalene, supraclavicular, infraclavicular and axillary approach. Of these the supraclavicular technique is commonly used for surgeries on the forearm and hand. This block which provides faster and dense anaesthesia targets the brachial plexus trunks. At this location, the sensory, motor and sympathetic innervation which is carried in three nerve structures is limited to a minute region. ${ }^{2}$. Bupivacaine has been the local anaesthetic most frequently used due to its longer duration of action but has a ceiling dose and potential for cardiotoxicity. This can be overcome by continuous regional anesthesia techniques using catheters or malleable needles but these have their own

\footnotetext{
1. Dr. Yogesh Dhakal

2. Dr. R. Rajbhandari

3. Prof. T. N. Agrawal
}

Address for correspondence:

Dr. Yogesh Dhakal

Dpartment of Anaesthesia

Nepalgunj Medical College

Kohalpur, Banke, Nepal

Email: drdhakalyogesh@gmail.com problems. Adjuvants added to local anaesthetics have been found to enhance the quality of the block and decrease the requirement of local anaesthetics.

Various studies have investigated several adjuvants, including opioids, clonidine, neostigmine, hyaluronidase, and bicarbonate ${ }^{3-7}$ Midazolam, a water-soluble benzodiazepine, is known to produce antinociception and to enhance the effect of local anaesthetic when given epidurally or intrathecally $y^{9.11}$. Midazolam produces this effect by its action on gamma amino butyric acid-A (GABA-A) receptors which have also been found in peripheral nerves ${ }^{12-14}$. However, very little data is available regarding the effect of adding midazolam to a local anesthetic solution in peripheral nerve blocks. We therefore sought to determine the onset time and analgesic efficacy of midazolambupivacaine combination compared to plain bupivacaine $0.5 \%$ for brachial plexus block.

\section{MATERIALS AND METHODS}

This study was carried out in Department of Anaesthesiology, Nepalgunj Medical College Teaching Hospital, Kohalpur. The duration of study was one year from October 2015 to October 2016. After Hospital Ethics committee approval and informed consent from all patients a prospective, randomized, double blinded study was undertaken in 60 ASA I and II patients of age group of 16 to $60 \mathrm{yrs}$ posted for elective or emergency upper limb surgeries under single injection supraclavicular block.

Patient belonging to ASA Grade III, IV and V, requiring surgery in both limbs or in any other area besides upper limb, documented hypersensitivity to any of the study drugs, patients on anticoagulant or antiplatelet therapy or with 
bleeding diathesis or coagulopathy, patient with infection at the puncture site, pregnant women and patients with $\mathrm{h} / \mathrm{o}$ cardiac, renal, hepatic and respiratory failure were excluded from study.

All patients were hospitalized at least a day before surgery and went through pre-anesthetic assessment and optimization, familiarization with Visual Analogue Scale (VAS). All the patients were pre-medicated with Pantoprazole $40 \mathrm{mg}$ and Diazepam $5 \mathrm{mg}$ orally at the night before surgery and the same dose in the morning of surgery. Patients were monitored using: ECG, non-invasive blood pressure, pulse oximeter. The baseline values for heart rate, systolic and diastolic blood pressure, $\mathrm{SPO}_{2}$ were recorded. Patients were randomly allocated using closed envelope technique, to received either $2 \mathrm{mg} / \mathrm{kg}$ of $0.5 \%$ Bupivacaine with $2 \mathrm{ml}$ isotonic NS (Group B) or $2 \mathrm{mg} / \mathrm{kg}$ of $0.5 \%$ plain Bupivacaine with $2 \mathrm{ml}(2 \mathrm{mg}$ ) of Midazolam (Group BM).

Patient were laid supine with the head turned to the opposite side. The interscalene groove and midpoint of clavicle were identified. Under strict aseptic preparation, subclavian artery pulsations were felt at a point 1.5 to $2.0 \mathrm{~cm}$ posterior and cephalad to midpoint of clavicle. A skin wheal was raised with local anesthetic just cephalo-posterior to the pulsations, supraclavicular brachial plexus block was performed through the same point with a 22-23-gauge needle, in a caudal, slightly medial and posterior direction. After obtaining paresthesia drugs were administered.

Onset of sensory block was assessed by response to atraumatic prick with the blunt needle in different areas innervated by radial, median, ulnar and musculocutaneous nerve. Onset of motor block was assessed by asking the patient to raise their hand or move their fingers. Successful block was considered when surgery was possible without any additional supplementation. After the block patients were enquired about discomfort during block procedure due to position or needle insertion. Assessment of sedation was done by University of Michigan Sedation Scale. (UMSS):1. Awake and alert 2. Minimally sedated, tired/sleepy, responding to verbal stimuli 3. Moderately sedated. somnolent/sleepy, responding to mild physical stimulus 4 . Deeply Sedated, deep sleep, responding to moderate to severe physical stimulus 5 . Unarousable.
Duration of surgery, NIBP, pulse rate, ECG, SPO2 and pain was assessed every 15 -minute interval till the end of surgery. Any adverse effects were noted. At the end of the surgery, the patients were shifted to the postoperative ward for clinical monitoring of vital signs, appropriate fluid therapy and other treatment.

Patients marked a circle around a point $(0,1,2,3$, etc.) on a $10-\mathrm{cm}$ scale, visual analogue scale pain score (VAS) indicating their level of pain between the two anchors (explained to them preoperatively), such as no pain to worst possible pain, for the intensity of pain assessment. The maximum intraoperative VAS pain score was recorded in each patient. Injection Voveran 75 $\mathrm{mg} I \mathrm{IM}$ was administered to treat moderate to severe pain (VAS pain score 4-10).

The patient was followed up till 24 hours post operatively during which the patient was evaluated for the duration of effective analgesia (time from brachial block to first request of analgesics) and the VAS pain score at that time. Pruritus, nausea and vomiting and other complications recorded if present. All these were recorded by direct questioning every 2 hour in early postoperative period (0-6hours) and every 4 hours in late postoperative period (7-24 hours). Any adverse events were recorded.

Statistical analysis was performed by using SPSS version 16 . Ordinal variables like SBP, MAP, DBP, HR and duration of analgesia was recorded as mean, standard deviation and significant was tested with student unpaired t-test. Nausea, vomiting, gender was recorded as frequency and significant was tested with Chi-square test. Result was considered significant at a $p$ value of $<0.05$.

\section{RESULTS}

Sixty ASA I and II patients of either sex aged between 16 to 60 years posted for upper limb surgeries under supraclavicular block were selected for the study. The study was undertaken to evaluate the efficacy of Midazolam ( $2 \mathrm{mg}$ ) as adjuvant to Bupivacaine $(0.5 \%)$ in comparison with plain Bupivacaine $(0.5 \%)$ with NS $(2 \mathrm{ml})$ for brachial plexus block by supraclavicular approach. The demographic parameters were comparable between the groups (Table I).

\begin{tabular}{|c|c|c|c|}
\hline Parameter & Group B & Group BM & $P$-value \\
\hline Age in years (mean \pm SD) & $30.13 \pm 13.444$ & $31.53 \pm 13.753$ & 0.692 \\
\hline Male/ Female & $26 / 4$ & $21 / 9$ & 0.691 \\
\hline Weight in Kg (mean \pm SD) & $56.43 \pm 7.96$ & $55.57 \pm 8.811$ & \\
\hline ASA I/ II & $27 / 3$ & $27 / 3$ & 0.026 \\
\hline Duration of surgery (mins) & $89.5 \pm 27.144$ & $76.67 \pm 14.641$ & \\
\hline
\end{tabular}

Table I: Demographic parameters 
Dhakal et al.: A Comparative Clinical Evaluation of Efficacy of Midazolam as an Adjuvant to Bupivacaine in Brachial Plexus Block by Supraclavicular Approach for Upper Limb Surgery

The mean time for onset of sensory and motor block was comparable in both groups. The mean time for onset of sensory block in Group B was $16.3 \pm 3.816$ min and in Group BM was $16.87 \pm 3.104 \mathrm{~min}(P>0.5)$. The mean time for onset of motor block in Group B was $21.37 \pm 4.311 \mathrm{~min}$ and in Group BM was $22.43 \pm 3.390 \mathrm{~min}(P>0.5)$. In both groups onset of sensory block was earlier than motor block.

The mean duration of analgesia in Group B was $243 \pm 57.545$ min where as in Group BM, it was $394.50 \pm 46.874 \mathrm{~min}$. The difference between duration of analgesia among groups was statistically significant ( $P$ value $<0.05$ ).

The mean VAS Score in Group B was $5.37 \pm 0.615$ where as in group $B M$, it was $4.53 \pm 0.937$. The results were statistically significant $(P<0.05)$.

Sedation score were comparable between groups. Heart rate, systolic blood pressure, diastolic blood pressure, mean arterial pressure, oxygen saturation were comparable between groups and did not change significantly in the intraoperative or postoperative period. No adverse events were encountered in either group of patients.

\section{DISCUSSION}

The advantages of performing upper limb surgeries under brachial plexus block are many but the limited duration of action in prolonged surgeries is a significant drawback. When

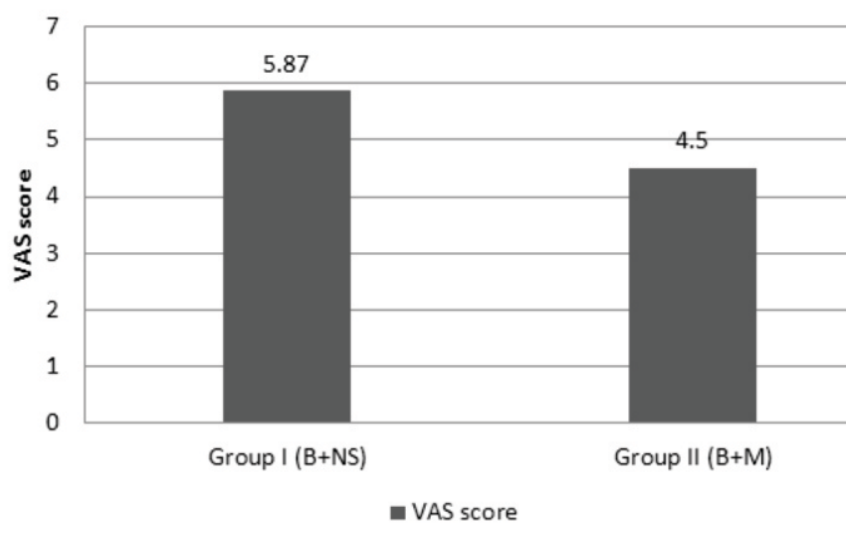

Figure 1: VAS score continuous catheter techniques are not available, adjuvants help by potentiating the action of local anaesthetics. The various adjuvants investigated include opioids, clonidine, dexamethasone, neostigmine, hyaluronidase and bicarbonate ${ }^{3-8}$.

We evaluated the efficacy and safety of midazolam when combined with bupivacaine for supraclavicular brachial plexus block. Total of 60 patients were included in study, 30 in each group. The age, gender, weight and duration of surgery were comparable in both group. The onset time of sensory block was $16.87 \pm 3.104 \mathrm{~min}$ in the midazolam group as compared to 16.3 $\pm 3.816 \mathrm{~min}$ in the control group. Similarly, onset of motor blockade was $22.43 \pm 3.390$ in midazolam group compared to $21.37 \pm 4.311$ in control group in our study. But in similar studies done by various authors both onset of sensory and motor blockade with midazolam was earlier than in control group ${ }^{15-18}$. They have explained this could be due to a local anaesthetic property of midazolam and its synergistic action with that of local anaesthetics. In our study onset of sensory block was earlier than motor blockade which was similar to finding of Dalvi $\mathrm{NP}^{18}$ and Fernandes $\mathrm{S}^{17}$. This was in contrast to studies conducted by Winne et $\mathrm{al}^{19}$ and Jarbo Batra et $\mathrm{al}^{16}$ where the motor block preceded the onset of sensory block. A study was conducted by Winnie et al $^{19}$ which studied separate onset and recovery of sensory and motor block in peripheral (mantle)and central (core) bundle within nerve trunks. Due to the somatotrophic configuration of nerve fibres in the trunks, motor block sets in earlier than sensory block. Motor fibres are located more peripherally than sensory fibres and hence a local anaesthetic injected peripherally will arrive at and begin to block motor fibres before it reaches the more centrally located sensory fibres.

The duration of sensory block (394.50 \pm 46.874$)$ was significantly prolonged $(P<0.05)$ in midazolam group compared to control group ( $243 \pm 57.545)$. Our result was similar to study done by various authors ${ }^{15-18}$. In post-operative period lower pain score were obtained in midazolam group compared to control group. The mean VAS Score in Group B $(5.37 \pm 0.615)$ was significantly higher compared to group BM (4.53 \pm 0.937$)$. The prolonged analgesia in Group BM could be due to the action of midazolam on GABA-A receptors present in the brachial plexus and thus producing antinociception. Various

\begin{tabular}{|c|c|c|c|}
\hline & Group B & Group BM & $P$-value \\
\hline $\begin{array}{c}\text { Onset of sensory block } \\
\text { (mean } \pm \text { SD) }\end{array}$ & $16.3 \pm 3.816$ & $16.87 \pm 3.104$ & 0.531 \\
\hline $\begin{array}{c}\text { Onset of motor block } \\
\text { (mean } \pm \text { SD) }\end{array}$ & $21.37 \pm 4.311$ & $22.43 \pm 3.390$ & 0.291 \\
\hline $\begin{array}{c}\text { Duration of analgesia } \\
(\text { mean } \pm \text { SD) }\end{array}$ & $243 \pm 57.545$ & $394.50 \pm 46.874$ & 0.00 \\
\hline
\end{tabular}

Table II: Time for onset of sensory and motor block and duration of analgesia 
authors have demonstrated the presence of GABA receptors in peripheral nerves. Bhisitkul et al. showed that axonal GABA receptors are present on both normal and regenerated sensory fibres in rat peripheral nerve ${ }^{13}$. Cairns et al. observed the presence of GABA receptors within the tempromandibular joint and that its activation could decrease the transmission of nociceptive signals ${ }^{14}$. The action of midazolam on GABA receptors is well known.

Sedation score was comparable between the group in our study. In study done by Jabro et al. they observer higher sedation score in midazolam group. The sedative effects of midazolam are observed due to partial vascular uptake of the drug and it's transfer to the central nervous system. Midazolam is highly lipophilic and diffuses faster in to the blood vessels. It has a rapid clearance $(6-11 \mathrm{ml} / \mathrm{kg} / \mathrm{min})$ and short half-life $(1.7-$ $2.6 \mathrm{hr})^{20}$. We studied midazolam at a dose of $2 \mathrm{mg}$ as others have used the similar doses for neuraxial blocks and brachial plexus block and have not observed any serious consquences.

Similar to other studies we did not find any significant difference in the pulse rate, systolic and diastolic blood pressure and arterial oxygen saturation intra-operatively and until 24 hours post-operatively. No any adverse events were observed during the period of study.

\section{CONCLUSION}

In conclusion addition of midazolam to bupivacaine for brachial plexus block prolongs the duration of analgesia with lower pain scores during post-operative period.

\section{REFERENCES}

1. Lund PC, Cwik JC, Vallesteros F. Bupivacaine- a new long acting local anaesthetic agent. A prelimnary clinical and laboratory report. Anesth Analg. 1976; 49:103-13.

2. Lanz E, Theiss $D$, Jankovic $D$. The extent of blockade following various techniques of brachial plexus block. Anesth Analg. 1983:62:55-8.

3. Bazin JE, Massoni C, Bruelle P, Fenies V, Groslier D, Schoeffler P. The addition of opioids to local anaesthetics in brachial plexusblock: the comparative effects of morphine, buprenorphine, and sufentanil. Anaesthesia. 1997;52:858-62.

4. Culebras X, Van Gessel E, Hoffmeyer P, Gamulin Z. Clonidine combined with a long acting local anaesthetic does not prolong postoperative analgesia after brachial plexus block but does induce hemodynamic changes. Anesth Analg. 2001;92:199-204.

5. Bone HG, Van Aken H, Brooke M, Burkle H. Enhancement of axillary brachial plexus block anesthesia by coadministration of neostigmine. Reg Anesth Pain Med. 1999;24:405-10.

6. Keeler JF, Simpson KH, Ellis FR, Kay SP. Effect of addition of hyaluronidase to bupivacaine during axillary brachial plexus block. Br J Anaesth. 1992;68:68-71.

7. Bedder MD, Kozody R, Craig DB. Comparison of bupivacaine and alkalinized bupivacaine in brachial plexus anesthesia. Anesth Analg. 1988;67:48-52.

8. Shrestha BR, Maharjan SK, Shrestha S, Gautam B, Thapa C, Thapa
PB et al. Comparative study between tramadol and dexamethasone as an admixture to bupivacaine in supraclavicular brachial plexus block. J Nepal Med Assoc. 2007;46(168):158-64.

9. Edwards M, Serrao JM, Gent JP, Goodchild CS. On the mechanism by which midazolam causes spinally mediated analgesia. Anesthesiology. 1990;73:273-7.

10. Nishiyama T, Yokoyama T, Hanaoka K. Midazolam improves postoperative epidural analgesia with continuous infusion of local anaesthetics. Can J Anaesth. 1998;45:551-5.

11. Kim MH, Lee YM. Intrathecal midazolam increases the analgesic effects of spinal blockade with bupivacaine in patients undergoing haemorrhoidectomy. Br J Anaesth. 2001;86:77-9.

12. Brown DA, Marsh S. Axonal GABA-receptors in mammalian peripheral nerve trunks. Brain Res. 1978;156:187-91.

13. Bhisitkul RB, Villa JE, Kocsis JD. Axonal GABA receptors are selectively present on normal and regenerated sensory fibers in rat peripheral nerves. Exp Brain Res. 1987;66: 59-63.

14. Cairns BE, Sessle BJ, Hu JW. Activation of peripheral GABA-A receptors inhibits temporomandibular jointevoked jaw muscle activity. J Neurophysiol. 1999;81:1966-9.

15. Raghu R, Indira R, Kiran M, Murthy R. A comparative study of $0.375 \%$ bupivacaine with midazolam and $0.375 \%$ bupivacaine for brachial plexus block in upper limb surgeries. Asian Pacific Journal of Health Sciences 2015; 2(4): 129-135.

16. Koj Jarbo MD, Yatindra Kumar Batra MD MNAMS, Nidhi Bidyut Panda MD. Brachial plexus block with midazolam and bupivacaine improves Analgesia. Can J Anaesth. 2005;52:822-6.

17. Fernandes S, Deshmukh V. Prospective Randomised Study to Evaluate the Efficacy of Midazolam as an Adjuvant to Local Anaesthetics in Brachial Plexus Block. International Journal of Contemporary Medical Research. 2016; Vol 3(5).

18. Dalvi NP, Salunkhay H, Mohite SN. A comparative study of addition of midazolam to lignocaine-bupivacaine vs only lignocaine-bupivacaine in brachial plexus block. Research and innovation in anaesthesia. 2016;1(1):5-9.

19. Winnie AP, Tay $\mathrm{CH}$, Patel KP, Ramamurthy S, Durrani Z. Pharmacokinetics of local anaesthetics during plexus blocks. Anesth Analg. 1977; 56:852-61.

20. Reeves JG, Fragen RJ, Vinik HR, Greenblatt DJ. Midazolam: phamacology and uses. Anesthesiology. 1985;62:310-24. 